Lexis Vol. XLIV (2) 2020: 575-617

\title{
La pluralización de haber en el español de los dominicanos en Madrid*
}

\author{
Manuel Peralta Céspedes \\ Universidad de Murcia
}

\section{RESUMEN}

En esta investigación, se presenta un estudio sobre los procesos de convergencia y divergencia en el contacto dialectal. La pluralización de haber está muy extendida en el español de la República Dominicana, pero es casi inexistente en el de Madrid. El análisis de estas variedades es útil para observar y explicar los procesos del contacto dialectal internacional. Se señala la importancia del estudio de la invariación dentro de la lingüística de la migración. Los resultados de esta investigación resaltan dos características principales: a) el prestigio de la variedad madrileña no influye en algunas variables lingüísticas entre los dominicanos en Madrid; b) la percepción y la frecuencia de la variable influyen en el proceso de convergencia y divergencia de los hablantes.

Palabras clave: contacto dialectal, pluralización de haber, español madrileño, español dominicano

\footnotetext{
"Los resultados de esta investigación fueron presentados en el Sociolinguistics Symposium 21 que se celebró del 15 al 18 de junio de 2016 en la Universidad de Murcia, España. Quiero agradecer a los doctores Eugenio Bustos Gisbert y Daniel Sáez Rivera, directores de mi tesis doctoral titulada Convergencia y divergencia en el español de hablantes dominicanos en Madrid, por sus valiosos comentarios a este trabajo. No obstante, soy responsable de cualquier error en el artículo.
} 
The Pluralization of haber in the Spanish of the Dominicans in Madrid

\section{AbSTRACT}

In this paper, we present a study about the process of convergency and divergency in the dialect contact. The pluralization of haber is very widespread in the Spanish of the Dominican Republic, but it is almost non-existent in Madrid. The analysis of these varieties is useful in order to observe and explain the process of international dialect contact. The importance of the study of non-variation within the linguistic of migration is point out. The results of the research highlight two main features: a) Madrilenian variety prestige does not influence some linguistic variables among Dominicans in Madrid; b) the perception and frequency of the variable impacts the process of convergence and divergence of the speakers.

Keywords: dialect contact, pluralization of haber, Madrilenian Spanish, Dominican Spanish

\section{Introducción}

Tradicionalmente, se considera incorrecto utilizar las formas babian/ bubieron/han habido/habrán/habrian/Debian haber delante de un sustantivo plural (e.g. Habian niños). Sin embargo, a pesar del esfuerzo de los gramáticos en corregir este uso (véase DPD 2005: haber, Martínez 1999: 2770), esta construcción está registrada en muchos países Hispanoamericanos y en algunas ciudades de España, aunque no con la misma extensión, como se presentará más adelante. En adelante nos ocuparemos de este fenómeno al que nos referiremos como 'pluralización de haber'.

El verbo haber, en su forma impersonal, denota la idea de "presencia o existencia de lo asignado por el sustantivo que lo acompaña y que va normalmente pospuesto" (RAE [DPD] 2005: haber). Como verbo impersonal, por tanto, se emplea generalmente en tercera persona de singular en todas las conjugaciones y en la perífrasis verbal (Habia muchas personas; Debia haber muchas personas). Esto se debe, según plantean las gramáticas tradicionales, a que el verbo haber al que nos referimos es transitivo y la frase nominal 
(en adelante FN) que le sigue es un complemento directo (CD) que no concuerda con él. Una prueba de ello es que dicha FN puede ser sustituida por el clítico correspondiente: bubo problemas $>$ los bubo ${ }^{1}$.

No obstante, los estudios sociolingüísticos han demostrado que este verbo está cediendo su carácter impersonal a personal, lo cual se evidencia en la concordancia con la FN que le acompaña. De esta manera, el sustantivo que lo acompaña pasa de ser CD a apreciarse como sujeto de la oración, produciéndose un reanálisis de la estructura (Hernández Díaz 2006: 802).

Hasta ahora, se han expuesto algunas hipótesis con el propósito de explicar por qué sucede este cambio. Sin ánimo de extendernos mucho en esta cuestión, algunos explican, por un lado, que el verbo impersonal transitivo ha sufrido un proceso de gramaticalización que ha resultado en la percepción del CD como sujeto debido a que "en él se concentra toda la atención" de la oración (Hernández 1975: 89-90); Kany (1976: 256) señala que dicha percepción no debería sorprendernos porque ya en latín existía esta discrepancia entre la noción psicológica (el sustantivo como sujeto) y la expresión gramatical (el sustantivo como complemento). Por otro lado, se ha planteado que los hablantes tienden a generalizar la regla de la concordancia sujeto-verbo debido a la "excepcionalidad que supone la existencia de un verbo impersonal transitivo" como haber y al hecho de que los verbos que denotan existencia en español sean verbos personales con sujeto, como estar, existir, ocurrir (RAE [DPD] 2005: haber). Finalmente, Hernández Díaz (2006: 804) adopta el término de "reanálisis" de Langacker (1977) para explicar que la pluralización de haber resulta de la reinterpretación del mensaje por parte del oyente que deriva, primero, en un cambio del significado y, finalmente, en un cambio de la forma del signo lingüístico.

\footnotetext{
A pesar de la veracidad de esta prescripción, Claes (2014: 103) señala que la concordancia existencial puede darse incluso ante la presencia del clítico, según documenta en el siguiente ejemplo obtenido por un informante en La Habana, Cuba: $Y$, entonces, los habian disciplinados, pero los habian que eran candelitas.
} 
En este estudio, presentaremos un análisis de esta variable en el español de los dominicanos en Madrid. Según las estadísticas del Padrón Continuo del Instituto Nacional de Estadística (INE), publicada el 1 de enero de 2015, los dominicanos han pasado a ser la tercera población mayoritaria de los hispanoamericanos con estancia en el Municipio de Madrid, con un total de 18.350 dominicanos ${ }^{2}$. Considerando que la concordancia existencial está muy extendida en la variedad de origen (Alba 2004) y que esta variante es casi inexistente en el habla de Madrid (DeMello 1991, Paredes García 2016), en las siguientes páginas se pretenden lograr estos objetivos:

a) Determinar los usos de la pluralización de haber entre los inmigrantes dominicanos en Madrid.

b) Señalar los factores lingüísticos, sociales y estilísticos que favorecen los usos de esta variante.

c) Comprobar si el uso de los dominicanos converge o no con el habla madrileña y presentar algunas hipótesis que puedan favorecer el comportamiento observado.

La ciudad de Madrid ofrece un espacio cultural multilingüe y pluridialectal enriquecedor del cual Sáez Rivera (2014) ha señalado que debería investigarse desde distintos ámbitos — como el paisaje lingüístico, el contacto dialectal, la escuela, el discurso, actitudes lingüísticas, etc.- entre los cuales ya se cuenta con algunas investigaciones, pero deberían ampliarse, incorporando métodos cualitativos de la antropología lingüística, la etnografía de la comunicación, el análisis de la conversación, entre otras. Nuestra investigación constituye una respuesta a ese llamado.

2 La posición señalada es importante si se considera que en el mismo informe del INE de 2014 ocupaban la quinta población mayoritaria. Las cifras señaladas pueden comprobarse en el siguiente enlace <http://www.ine.es/jaxi/Tabla.htm?path=/t20/e245/ p05/a2015/10/\&file=00028003.px> [Consultado el 02 de junio de 2016] . 


\subsection{La extensión de la pluralización de haber en Hispanoamérica y España}

La pluralización de haber impersonal se ha registrado en distintas variedades del español en Hispanoamérica y España. En Hispanoamérica, el fenómeno se ha documentado de manera más extendida en Caracas (Bentivoglio y Sedano 1989, 1992, 1996; D’Aquino 2004, 2008), El Salvador (Quintanilla Aguilar 2009), La Paz (DeMello 1991), Puerto Rico (Rivas y Brown 2012, Claes 2014), Santo Domingo (Alba 2004, Claes 2014), entre otros. También se documenta, aunque de manera menos extendida, en Santiago de Chile (Soler 2012), Lima (DeMello 1991) y La Habana (Claes 2014). En otras variedades de Hispanoamérica existe, aunque menos extendido, como en la ciudad de México (Lastra y Butragueño 2016, Soler 2012) y en Buenos Aires, Argentina (Soler 2012). Tras estudiar el fenómeno en nueve ciudades Hispanoamérica, DeMello (1991: 468) llega a señalar que este fenómeno es ‘muy común’ en el español hablado culto hispanoamericano. Colombo y Soler (2003) señalan que este y otros fenómenos en el español mexicano son el reflejo de nuevas normas que se están imponiendo. En España, se ha observado en Canarias (Almeida y Díaz Alayón 1988), Valencia (Gómez Molina 2013; Blas Arroyo 1996, 2016), Cataluña (Blas Arroyo 1996: 177) y en la isla de El Hierro (Pérez Martín 2007).

\subsection{La convergencia y divergencia dialectal}

En su singular obra, Dialectos en Contacto, Trudgill (1986) adoptó al contexto de los estudios lingüísticos la teoría de la acomodación del habla propuesta por Giles, Taylor y Bourhis (1973), la cual se fundamenta en los conceptos de convergencia y divergencia. De acuerdo con Giles et al. (1973: 90), la convergencia es el comportamiento [o estrategia comunicativa, véase Moreno Fernández 1999-2000] que los hablantes exhiben cuando intentan adaptar las características de su habla a las características del habla de quienes les rodean. Por otro lado, la divergencia es una estrategia que los hablantes usan deliberadamente para afirmar o mantener su 
propia identidad y así marcar sus diferencias frente a los demás individuos.

Trudgill sugiere que la frecuencia de una variable es determinante en la convergencia del hablante cuando expresa que "uno no cambia la manera de pronunciar una palabra en particular hasta que la ha escuchado pronunciar de manera distinta con tanta frecuencia que la pronunciación original empiece a resultar inusual en otros y aun en nosotros mismos" (Trudgill 1986: 49) [Las cursivas son nuestras]. Asimismo, podemos afirmar, como se propondrá en este artículo, que la baja frecuencia de la variable favorece la divergencia del hablante. Pero la divergencia que resulta de esta condición es inconsciente, no deliberada, por lo que se distingue de la divergencia deliberada que se fundamenta en los sentimientos de identidad lingüística.

\subsection{La dialectología perceptual y la lingüística de la migración}

En el contacto dialectal es común comparar los usos del dialecto materno (en adelante $\mathrm{D}_{1}$ ) con el dialecto receptor (en adelante $\mathrm{D}_{2}$ ). Un hablante de un dialecto que ha tenido contacto con otro dialecto, bien de forma física a través de un hablante o a través de los medios de comunicación, notará seguramente diferencias respecto a su dialecto materno. Si el otro dialecto con el que se ha tenido contacto tiene como referencia una misma lengua estándar, las diferencias serán menores. Este contacto es el que se conoce como contacto dialectal trasnacional. En cambio, si el contacto ha sido con un dialecto que tiene como referencia una lengua estándar diferente a la propia, las diferencias serán mayores. A este contacto se le denomina contacto dialectal internacional.

En el contexto referido también es común encontrar personas (unas más que otras) que adoptan características del $\mathrm{D}_{2}$ (Chambers 1992). No es nuestro propósito presentar los distintos factores lingüísticos y extralingüísticos que favorecen o no la adquisición de las características del D2 sobre los cuales se ha argumentado bastante en la bibliografía (véase Trudgill 1986, Milroy 1987, Siegel 2010, Kerswill 1992, Holmes y Kerswill 2008). Por ahora, solo me refe- 
riré muy brevemente a la influencia de las actitudes lingüísticas para los propósitos de la argumentación en este apartado.

Las actitudes lingüísticas hacia el $\mathrm{D}_{2}$, como al propio $\mathrm{D}_{1}$, favorecerán o no la adquisición de las nuevas características dialectales que se observan a través del contacto dialectal. Sin embargo, una de las limitaciones que se les ha atribuido a las investigaciones de actitudes lingüísticas es que analizan la percepción lingüística del hablante con estímulos globales hacia una lengua o un dialecto y dejan al margen las percepciones hacia características lingüísticas específicas y su localización geográfica (Preston 2013). Motivado por estas circunstancias, Dennis Preston (1989) desarrolló la dialectología perceptiva para responder a las limitaciones de los estudios desde la sociología del lenguaje y la sicología social, así como para valorar las actitudes lingüísticas de los hablantes que se habían dejado al margen en la dialectología y la sociolingüística tradicionales (Cramer 2016).

La dialectología perceptiva estudia la percepción de la variación dialectal según el entendimiento de aquellos que no son especialistas en la lengua (en la bibliografía se usan los términos folk linguistics o nonlinguistics para referirse a estos informantes). Esta disciplina lingüística explora las conexiones entre el uso de la lengua y las actitudes lingüísticas que ya William Labov (1972) había sugerido implícitamente en el estudio de los africanos americanos en Nueva York (Cramer 2016).

Preston (1999) y sus primeros seguidores en los Estados Unidos y alrededor del mundo (Niedzielski 1999, Inoue 1996, Montgomery 2007), inspirados en los trabajos realizados por investigadores holandeses y japoneses, aplicaron la metodología de dibujo de mapas mentales donde se representaban las percepciones de los participantes. Sus primeros trabajos mostraban las áreas más estigmatizadas y las de mayor prestigio lingüístico según los participantes. No obstante, los trabajos más recientes de sus seguidores se limitan a observar cómo un Estado específico percibe su localidad internamente y en los Estados Unidos (Cramer 2016). Además de la señalización de las pronunciaciones dialectales en un mapa, otras 
investigaciones se enfocan en la percepción de usos dialectales en comparación con la lengua estándar (Al-Banyan y Preston 1998), y la comparación con otras áreas dialectales (Plichta y Preston 2005).

Las investigaciones en este campo han resaltado que las actitudes lingüísticas pueden estar relacionadas concretamente con las características lingüísticas individuales, pero dicha relación no es tan simple, ya que, en unas ocasiones, algunas características acústicas son las que parecen desencadenar una actitud, mientras que, en otras, la frecuencia de una variante $u$ otra provoca los efectos de los juicios sociales, como la elisión de la -r en la ciudad de Nueva York, según Labov 1966, citado por Preston 2013) [Las cursivas son nuestras].

Las investigaciones sobre dialectología perceptiva, sin embargo, no se enfocan en analizar la influencia que tiene la migración y el contacto dialectal en la formación de las actitudes lingüísticas. Al respecto, Caravedo (2009, 2010) ofrece interesantes reflexiones conceptuales en torno a la percepción y a la importancia de la dimensión subjetiva en el contacto conflictivo producido por la migración. Esta investigadora sostiene que la percepción cognitiva que se desarrolla en los primeros años de vida y le permite a una persona adquirir una variedad, tiene un período óptimo a los 9 y 10 años — como establece Labov (en red)_, pero luego "va decreciendo progresivamente de modo natural hasta que se adquiere completamente la propia variedad" (Caravedo 2010: 17). Señala, además, que dicha percepción suele reactivarse cuando se confronta la variedad adquirida en la infancia con otras variedades distintas, producto de la migración; no obstante, argumenta que en los contextos migratorios surge una 'percepción selectiva' por medio de la cual los hablantes dirigen la atención a determinados fenómenos (Caravedo 2009).

Por otro lado, desde la lingüística alemana, se ha propuesto el concepto de Migrationslinguistik ('lingüística migracional' o 'lingüística de la migración', según defienden Zimmermann y Morgenthaler 2007) como una subdisciplina lingüística que se encargue de estudiar estos contextos y los desarrollos lingüísticos 
que se producen en ellos. Enfocándose en los migrantes, dentro de la lingüística de la migración se ha señalado la necesidad de analizar los efectos en la sociedad de origen (Kluge 2005, Gugenberger 2006) y se han estudiado los efectos en las actitudes de la sociedad receptora (Morgenthaler García 2006, Krefeld 2004). De estas dos dimensiones de análisis, la más desarrollada es la de los efectos de la migración en la sociedad de origen ${ }^{3}$. Algunas vías para analizar el impacto de la migración en la sociedad receptora derivan de la lingüística migratoria histórica, como las conquistas coloniales de los estados europeos entre los siglos XVI y XIX, a través de las cuales se formaron idiomas criollos con base en inglés, francés, español y portugués; también resulta interesante para la lingüística de la migración los pidgins y las lenguas francas que surgieron en los puertos y las metrópolis comerciales de Asia y América (Stehl 2011: 35).

Son mínimos los esfuerzos que se han hecho, hasta donde hemos investigado, para estudiar los efectos de la migración en la variedad receptora madrileña. No obstante, Sáez Rivera (2015) señala, en su estudio sobre el paisaje lingüístico de Madrid, la posibilidad de acomodación hacia la variedad dominicana en las zonas donde estos tengan mayor peso demográfico y hasta documenta un caso de un español, dueño de un antiguo negocio, quien utilizó rasgos del español dominicano en un cartel para atraer, posiblemente, a esta clientela.

La dialectología perceptiva y la lingüística de la migración, adoptando y readaptando las metodologías que se utilizan en la sicología social, la sociolingüística, la sicología cognitiva, el contacto dialectal, entre otras disciplinas, han enriquecido nuestro conocimiento acerca de las condiciones sociales, lingüísticas y cognitivas que favorecen la adquisición de las variantes del D2, aunque no existe un consenso general en la aplicación de los detalles y las hipótesis no se demuestren de la misma manera en todos los contextos.

\footnotetext{
3 Para un estado de la cuestión sobre estudios románicos y americanos, consúltese el capítulo dos de Peralta Céspedes (2016) y Siegel (2010).
} 
Algunas de estas son las siguientes: una persona con 7 años o menos puede adquirir con facilidad los usos nativos del D2, mientras que los mayores de 14 años no podrán (Chambers 1992); el principio de la edad de Chambers se aplica a las características fonológicas/ fonéticas, ya que las morfológicas y sintácticas se pueden adquirir en edades mayores (Kerswill 1994); los primeros años de residencia son determinantes en la adquisición fonética del D2 (Foreman 2000) mientras que el mayor tiempo de residencia favorece la adquisición de usos morfosintácticos del D2 (Palacios 2007, Peralta Céspedes 2015b); las redes sociales fuertes con hablantes del D2 favorecen la adquisición de usos de la variedad receptora (Milroy 1987, Kerswill 1994); el reemplazo léxico se adquiere más rápido que el fonológico y el fonético (Chambers 1992); las variantes más marcadas en el D1 tienden a sustituirse por las equivalentes en el D2 (Bortoni-Ricardo 1985: 175).

\section{El corpus y la metodología}

Los datos que se analizaron en este trabajo fueron obtenidos a través de una entrevista aplicada durante los meses de abril y mayo de 2013 en la ciudad de Madrid. Se entrevistaron a 100 dominicanos de origen, por lo que no se consideraron a aquellos que habían nacido en España. En un principio se intentó contactar a los informantes al azar. Sin embargo, esto no resultó efectivo porque los dominicanos elegidos, de estrato sociocultural bajo y medio, se mostraron desconfiados, por lo que no querían ofrecer informaciones personales. Por esta razón, se decidió aplicar la técnica de muestreo bola de nieve ('snowball sampling', véase Goodman 1961), una técnica no probabilística de muestreo en la que un informante -o unos informantes primarios - pone en contacto al investigador con otros informantes de la misma red social (amigos, familiares, conocidos) con las características necesarias hasta alcanzar el número de informantes que encajaran en los requerimientos de la muestra preestratificada. Esta técnica permitió allegarnos a informantes en las 
localidades de mayor conglomerado de dominicanos como Prosperidad, Cuatro Camino, Tetuán, San Cristóbal, Villaverde Alto, etc.

De los 100 informantes, solo en 82 entrevistados se encontró algún ejemplo con la variante analizada en este estudio. Como en las entrevistas se consideraron a informantes a partir de los 8 años de edad, estas duraron entre 25-35 minutos en los niños y adolescentes y 40-80 minutos en los jóvenes y adultos. Aunque el tiempo de la entrevista fue mayor, el tiempo considerado para esta investigación fue de 46 horas de grabación correspondiente a las entrevistas semiinformal e informal.

En la entrevista semi-informal, se realizaron algunas preguntas que perseguían elicitar el uso de haber en la respuesta de los informantes. En la entrevista informal, los entrevistados hablaban sobre temas generales relacionados a la familia, la escuela, el viaje desde República Dominicana a España, experiencias de viaje en España, entre otros.

Las transcripciones fueron realizadas por quien suscribe este estudio utilizando el programa Express Scribe ${ }^{4}$. Luego de seleccionar los casos de haber seguido de una $\mathrm{FN}$ plural (Habian vecinos adolescentes) o de una entidad colectiva (Habian mucha gente), se codificaron atendiendo a los siguientes factores lingüísticos, entre el amplio número de factores que suele considerarse en estos estudios en la bibliografía especializada:

a) Rasgo semántico de la FN (humano/no humano); estructura verbal (verbo sintético [simple o compuesto]/perífrasis verbal); posición de la FN (antepuesta, pospuesta, elidida); marcas de pluralidad en la FN (presencia/ausencia de modificador/ entidad colectiva); tiempo verbal (pretérito/imperfecto/forma infinitiva/otros).

Además, se consideró un factor estilístico, distinguiendo entre las preguntas que perseguían elicitar la variante en la entrevista

\footnotetext{
4 Se puede acceder a este software en: https://www.nch.com.au/scribe/es/index.html? ns=true \&msclkid=1bd258efo9519efb2270481b290a9eb
} 
semi-dirigida (e.x. ¿Has ido a una fiesta de cumpleaños/partido de futbol, etc.?, ¿Cuéntame sobre las cosas que había allí?) de aquellas que surgieron a lo largo de la entrevista informal:

b) Estilo (semi-informal/informal)

También se consideraron los siguientes factores sociales:

c) Sexo (hombre/mujer); edad (8-14 años [pre-adolescentes]/15-18 años [adolescentes]/19-39 años [jóvenes]/ >40-60 años [adultos]); tiempo de estancia en Madrid (1-2 años/3-4 años/5 años o más); ocupación (estudiante/empleado/parado); nivel de instrucción (alto/medio/bajo).

Se realizó un análisis multivariante de regresión logística de los datos utilizando GoldVarb 2001 (Robinson, Lawrence y Tagliamonte 2001) para poder determinar los variables más influyentes, tras la aplicación de algunas herramientas que permiten conformar el modelo estadístico (Binominal, 1 Level/ Binominal Up \& Down) considerando todos los factores al mismo tiempo (ver Tabla 2).

En el análisis, la pluralización de haber constituye la variable independiente (Aplication Value) del estudio, por lo que el análisis de regresión multiple que se presentará se realiza para determinar el peso probabilístico de los factores de cara a esta variable.

En nuestro estudio no hubo ningún caso de concordancia con el presente de indicativo (hayn, haen, hain), por lo que se descartó esta variante, a pesar de que se ha documentado en otras variedades entre las cuales está el español dominicano (Claes 2014) 5 . No

\footnotetext{
5 Resulta interesante que en el corpus del habla dominicana de este estudio no haya surgido la variante del presente de indicativo (hay>hayn), como documenta Claes (2014) también en Santo Domingo. Que recuerde, tampoco ha sido señalada por otros lingüistas nacionales, aunque Vaquero (1996) indica que existe en el habla dominicana. Quizá la explicación haya que buscarla en la metodología utilizada, ya que Claes aplicó, además de la entrevista semidirigida, un cuestionario escrito y una lectura donde los informantes debían seleccionar la respuesta de entre un conjunto de opciones. Si los casos que refiere derivan de los dos últimos instrumentos, entonces podrían considerarse como casos de ultracorrección, al menos en las variedades donde no se reporte en estilos espontáneos. Al consultar su tesis doctoral se puede comprobar que los ejemplos de la entrevista semidirigida corresponden al español de San Juan (Puerto Rico).
} 
obstante, hubo algunos casos donde el sujeto ello aparece explícitamente, tanto delante de FN plural como en (1), como de FN singular como en (2). En (1), la presencia de ello impide claramente la concordancia con el CD. Cabe señalar que este pronombre expletivo es típicamente dominicano (Henríquez Ureña 1939, Jiménez Sabater 1975, y Hinzelin y Kaiser 2007).

(1) Entonces ello hay veces que, por ejemplo, yo vuelvo y la llamo y le digo: "venme a buscar a tal hora" y nos vamos juntas. (mujer, adolescente, +5 años, estudiante, nivel medio)

(2) Ello hay un hospital aéreo... (hombre, adulto, +5 años, parado, nivel alto)

Tampoco se codificaron los tres ejemplos de (3), ya que estos casos van más allá de los límites de la variante estudiada porque se implica la persona, además del número:

(3) Éramos las únicas que babiamos, vamos, en mi facultad. (mujer, adulta, +5 años estancia, empleada, nivel alto)

Yo, por ejemplo, yo tenía mi trabajo fijo porque yo duré veinte y tantos años de cocinera en una casa de gente de mucho dinero que habiamos siete personas trabajando (mujer, adulta, +5 años, empleada, nivel medio)

Bueno, es que Madrid es una ciudad grande donde habemos muchas, muchas personas. (mujer, adulta, 1-2 años, empleada, nivel alto)

Los resultados generales se muestran a continuación.

\section{Resultados y análisis}

Con el propósito de ofrecer la mayor cantidad de datos que sirvan de comparación a futuras investigaciones, en la Tabla 1 se presentan los usos generales de baber de nuestro corpus. El análisis que nos interesa, sin embargo, se centra en los casos de haber seguido de una frase nominal (FN) en plural, que es donde el fenómeno presenta mayor variación entre las distintas variedades hispanoamericanas. 
Tabla 1. Uso general de haber en el habla de los dominicanos en Madrid

\begin{tabular}{|c|c|c|c|c|c|}
\hline & n. & $\%$ & & $\mathrm{~N}$ & $\%$ \\
\hline Hay & 363 & 54,18 & Había + FN singular & 94 & 30,62 \\
\hline Otros tiempos & 307 & 45,82 & Había(n) + FN plural & 213 & 69,38 \\
\hline N. & 670 & 100,00 & N. & 307 & 100,00 \\
\hline
\end{tabular}

Entre los dominicanos en Madrid, la pluralización de haber $(67 \%, n=143)$ duplica el porcentaje de uso de la forma impersonal (33\%, n=70), según se observa en el Gráfico 1. El habla de los dominicanos diverge ampliamente del español de la variedad receptora si se considera que, en el habla de Madrid, según un estudio realizado por Paredes García (2016: 219), la pluralización de baber se observó escasamente, alcanzando solo un $2.1 \%$ de casos; en consecuencia, el investigador señala que este fenómeno se ha iniciado en Madrid, aunque sea de forma “incipiente” (Paredes García 2016: 220). Los 12 casos registrados por Paredes García superan a los 2 que ya había registrado Quilis (1983: 94) en la norma culta de Madrid, aunque ambos siguen siendo escasos.

Gráfico 1. Distribución de la forma pluralizada y no pluralizada entre los dominicanos en Madrid

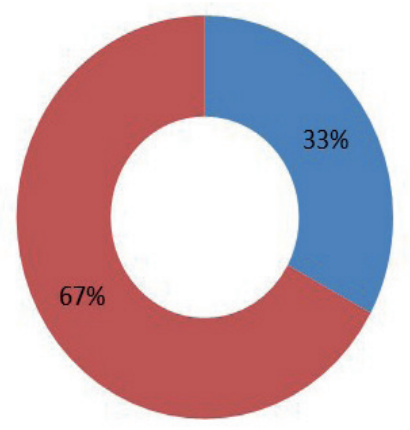

- Forma impersonal

- Forma pluralizada 
En nuestro corpus, la forma pluralizada de haber se presenta incluso ligeramente mayor respecto al $61,2 \%$ que registra Claes (2014: 11) del uso de esta variante en Santo Domingo. Claramente, los datos señalan la extensión del fenómeno en las comunidades dominicanas a ambos lados del Atlántico, extensión que también se presenta principalmente en las ciudades venezolanas de Táchira (82\%, Freites 2008$)$ y Caracas $(47.9 \%$, Bentivoglio y Sedano 1989; $66 \%$, D’Aquino 2008), mientras que en La Habana (60,6\%, Claes 2014), en Puerto Rico (58\%, Rivas y Brown 2012), y en el español peninsular, en Valencia — Blas Arroyo (2016) presenta una extensión mayor $(52 \%, \mathrm{n}=257)$ que la ya presentada por Gómez Molina (2013; $46 \%, \mathrm{n}=127)$ - aunque en esta localidad la influencia se asocia principalmente al contacto lingüístico entre el español y el catalán.

En la Tabla 2 se presentan los resultados del análisis multivariable utilizando GoldVarb 2001, el cual permite determinar los factores más significativos relacionados al uso de la pluralización de haber. Los valores entre corchetes corresponden a los factores que no fueron escogidos por el programa como significativos. Se decidió presentar estos datos, no obstante, para mostrar su peso probabilístico. Comúnmente, suele considerarse favorable cuando el contexto logra un peso probabilístico sobre .50 y desfavorecedor cuando está por debajo de .50. Sin embargo, Tagliamonte (2006) señala que, aunque esto es generalmente cierto, no es la mejor manera de interpretar el peso probabilístico (factor weight); en cambio "it is the relative position of factor weights, vis-à-vis each other, that is the relavent criterion for interpretating the results" (Tagliamonte 2006: 145). Al interpretar los resultados, los factores más influyentes serán aquellos que muestren los más altos valores según estos tres criterios (Poplack y Tagliamonte 2001: 92; Tagliamonte 2002: 731):

a) Significancia estadística, la cual se determina por los factores sobre .50 según el peso probabilístico.

b) Fuerza relativa (relative strength), que se establece al determinar el rango de los factores. 
c) El orden de la jerarquía, que se determina al ordenar los factores de mayor rango sobre los de menor rango.

A estos criterios, hay que añadir la significancia estadística del modelo, obtenida por el p-valor de Chi-cuadrado $\left(\mathrm{X}^{2}\right)$, que es la que establece si un factor es significativo estadísticamente y, por tanto, entra en el modelo que se desea conformar, y si no, entonces se descarta (o se presenta señalizado como tal). En nuestro caso, por ejemplo, en la Tabla 2 se presentan entre corchetes los factores que no resultaron significativos en el modelo.

\subsection{Factores lingüísticos}

\subsubsection{Rasgo semántico de la FN}

Este factor lingüístico es uno de los que más se ha observado en el estudio de haber en plural. La idea que sustenta la observación de este contexto es que el carácter humano de una FN se asocia con la idea prototípica de sujeto. En muchas comunidades se ha demostrado la hipótesis de que la pluralización de haber se favorece cuando el argumento de la $\mathrm{FN}$ es [+ humano], como en (4) que cuando es [- humano], como en (5).

(1) ...entonces yo había llegado nueva a la clase y babian chicas que me conocían... (41)

(2) Había algunos hoteles... Es una isla de muchos arraigos pero no babian universidades. (14)

Tabla 2. Resultados del análisis multivariable de los factores internos y externos seleccionados como significativos y no significativos (entre corchetes) de la probabilidad de uso de la pluralización de haber en el habla de los dominicanos en Madrid a través del análisis Binominal Up and Down desarrollado en GoldVarb 2001.

\begin{tabular}{lccc}
\hline Factores & Factor weight & $\%$ & $\mathrm{~N}=213$ \\
\hline Marcas de pluralidad en la FN & & & \\
Ausencia de modificador & $\mathbf{. 6 6}$ & 76 & 50 \\
Presencia de modificador & $\mathbf{. 6 5}$ & 76 & 102 \\
Entidad colectiva & .17 & 32 & 61 \\
Rango & 49 & & \\
\hline
\end{tabular}




\begin{tabular}{|c|c|c|c|}
\hline Factores & Factor weight & $\%$ & $\mathrm{~N}=213$ \\
\hline \multicolumn{4}{|l|}{ Posición de la FN } \\
\hline Pospuesta & .53 & 65 & 187 \\
\hline Otros (Antepuesta o elidida) & .29 & 50 & 26 \\
\hline Rango & 24 & & \\
\hline \multicolumn{4}{|l|}{ Rasgo semántico de la FN } \\
\hline+ Humano & {$[.55]$} & 63 & 117 \\
\hline -Humano & {$[.44]$} & 64 & 96 \\
\hline \multicolumn{4}{|l|}{ Estructura verbal } \\
\hline Sintético (simple y compuesto) & {$[.51]$} & 64 & 208 \\
\hline Perífrasis & {$[.15]$} & 40 & 5 \\
\hline \multicolumn{4}{|l|}{ Edad } \\
\hline 19-34 (Jóvenes) & .63 & 71 & 83 \\
\hline 15-18 (Adolescentes) & .51 & 62 & 40 \\
\hline$>40$ (Adultos) & .40 & 54 & 37 \\
\hline 8-14 (Pre-adolescentes) & .36 & 60 & 53 \\
\hline Rango & 27 & & \\
\hline \multicolumn{4}{|l|}{ Sexo } \\
\hline Hombre & {$[.50]$} & 66 & 95 \\
\hline Mujer & [.49] & 61 & 118 \\
\hline \multicolumn{4}{|l|}{ Tiempo de estancia } \\
\hline $1-2$ años & {$[.37]$} & 58 & 31 \\
\hline 3-4 años & {$[.51]$} & 63 & 55 \\
\hline 5 años o más & {$[.53]$} & 65 & 127 \\
\hline \multicolumn{4}{|l|}{ Ocupación } \\
\hline Estudiante & {$[.52]$} & 63 & 114 \\
\hline Empleado & {$[.53]$} & 63 & 60 \\
\hline Parado & {$[.45]$} & 66 & 39 \\
\hline \multicolumn{4}{|l|}{ Nivel de instrucción } \\
\hline Bajo & [.60] & 70 & 65 \\
\hline Medio & {$[.44]$} & 59 & 133 \\
\hline Alto & {$[.59]$} & 73 & 15 \\
\hline \multicolumn{4}{|l|}{ Estilo } \\
\hline Semi-dirigido & {$[.47]$} & 60 & 135 \\
\hline Natural & {$[.56]$} & 70 & 78 \\
\hline
\end{tabular}

Input .66

Log likelihood $=-115,640$

Significance $=0,042$ 
Nuestros datos confirman esta hipótesis, ya que se observó que el contexto [+ humano] favorece más el uso de la pluralización de haber (.55) que cuando el referente es [- humano] (.44). Aunque el factor resultó significativo al correlacionarse con la variable independiente ( $\mathrm{p}=0.041)$, no resultó elegido al compararse junto a todos los factores, según el análisis de regresión múltiple desarrollado por el que se ha establecido el modelo estadístico que mejor explica la relación entre las variables.

Los datos obtenidos se muestran en consonancia con los que se ha observado en Caracas (Bentivoglio y Sedano 1989), Puerto Rico (Rivas y Brown 2012), El Salvador (Quintanilla 2009), Mérida (Venezuela) (Domínguez et al. 1998), entre otras comunidades.

\subsubsection{Estructura verbal}

Según la estructura verbal, el verbo haber puede presentarse en las formas simples (6), en las formas compuestas (7) y en las formas de perífrasis, como en (8). En nuestro corpus, sin embargo, no hubo casos de pluralización de haber en la forma compuesta, por lo que estos contextos se etiquetaron en la codificación como [verbo sintético: simple y compuesto] y [perífrasis verbal].

(1) Según cuentan los noticieros, babian muchas puertas que estaban cerradas (40)

(2) Bueno, menos trabajo. Oh, bueno, no, igual. El trabajo igual. Nunca ha habido... (65)

(3) ahí suelen baber algunas diferencias, pero al final se discute y se quedan, se queda tranquila la cosa. (39)

En nuestros datos, la forma simple es la estructura principal (.51, $\mathrm{n}=134$ ) para la pluralización de haber existencial, en comparación con los casos de perífrasis verbal $(.15, \mathrm{n}=2)$. La variable tampoco fue elegida entre los factores más relevantes según el modelo de regresión múltiple obtenido. Ahora bien, aunque se podría argumentar que el índice de probabilidad no resulta muy esclarecedor, hay que recordar que, según la frecuencia observada (Tabla 2), la forma simple fue la variante que obtuvo casi la totalidad de casos de 
la muestra y en ella predominó la forma pluralizada de haber. Otro factor que pudo influir en el resultado de la regresión múltiple es que los casos de perífrasis verbal fueron casi anecdóticos en la muestra. Los resultados obtenidos se asemejan al de otras comunidades como Caracas (D’Aquino-Ruíz 2004), en donde la concordancia es más común cuando haber no forma parte de una perífrasis verbal. Por el contrario, los resultados de este estudio se distinguen de los de otras comunidades de habla como México (Montes de Oca 1994), El Salvador (Quintanilla 2009) y Valencia (Blas Arroyo 1996, 2016) en donde el contexto de la perífrasis verbal fue más determinante en la pluralización de haber.

\subsubsection{Marcas de pluralidad de la FN}

La idea que sustenta la elección de este factor es que la pluralización de haber es más común cuando el sustantivo de la FN es reforzado por otros elementos que indiquen marcas de plural. De esta manera, se distinguió entre las FN con ausencia de modificador (9) de aquellas con presencia de modificador (10). Ahora bien, en ocasiones, la idea de pluralidad no depende del número de los elementos que acompañan al sustantivo ni por el número del sustantivo, sino que aparece implícita por la idea de colectividad de la FN. Estos casos se codificaron como 'entidad colectiva' (11):

(9) Entonces bubieron medidas que el presidente no supo, para mí, no la supo llevar (5)

(10) ... también habian muchos restaurantes (23).

(11) Aquí habian gente que en la comisión ganaban 5 mil euros (25)

Este factor fue el más significativo en el modelo de regresión múltiple constituido (Tabla 2). Nuestros datos contradicen la hipótesis señalada debido a que los dos primeros contextos favorecen notablemente la pluralización de haber. Incluso, pareciera que la pluralización de haber es más esperada cuando la FN no está integrada por modificadores (.66) que cuando sí los hay (.65). Nótese, además, que la pluralidad que sugiere gente en (11) afecta no solo a habian, sino también a ganaban. Haría falta profundizar más el 
análisis para determinar si la tendencia observada de mayor pluralización ante la falta de modificadores pueda estar vinculada a la pérdida de la $-s$ que está tan extendida en la variedad vernacular de los dominicanos, aunque se ha demostrado que, producto del contacto dialectal, este segmento suele reponerse con frecuencias mayores que las que se han reportado en la isla (Peralta 2015a). Es probable que, según se observa en (12), la pérdida de las marcas de número en la FN facilita la expresión del número en la flexión verbal, siempre y cuando exista un elemento que aporte valor nocional plural, como muchísima.

(12) Cuando yo vine habian muchísima posibilidad de trabajo (12)

La variable tampoco resultó significativa en el habla de los salvadoreños (Quintanilla 2009) ni en el español de Santiago de Chile y Caracas (Díaz-Campos 1999-2000). Incluso, Quintanilla (2009) apunta que los que no tenían modificadores favorecían más la pluralización. No obstante, la idea de que la presencia de un modificador contribuye al uso plural de haber se ha observado en Venezuela (Bentivoglio y Sedano 1989, Díaz Campos 2000).

\subsubsection{Posición de la FN}

La posición pospuesta de la FN es la forma prototípica de las oraciones existenciales dado que los verbos existenciales como haber se caracterizan por introducir una información nueva - total o parcial- en el discurso (Hernández Díaz 2014: 127). Por tanto, la FN realiza la función discursiva de foco de la oración —es decir, la información nueva- y el verbo se constituye en el tópico o la información conocida entre los interlocutores. Las oraciones existenciales a menudo son all new informativamente. En estos casos, toda la oración, incluyendo el verbo, sería foco (sentential focus).

Además de la posición pospuesta (13), la FN puede anteceder en una oración al verbo haber (14), como también puede presentarse de forma implícita (15). En el análisis probabilístico, sin embargo, se contabilizaron conjuntamente las formas antepuestas y elididas, debido a la reducida frecuencia obtenida $(n=13)$, en contraste con 
el número de ejemplos de haber en plural obtenidos en la forma pospuestas $(\mathrm{n}=123)$.

(13) babian muchas flores (23)

(14) muchos turistas había (98)

(15) que no hay trabajos. Ante(s) habían de sobra (92)

La posición de la FN fue el segundo factor lingüístico más significativo en el análisis de regresión múltiple desarrollado. En este factor el contexto más favorecedor fue la posición pospuesta (.53), mientras que los otros contextos en conjunto lograron una probabilidad mucho menor (.29).

Aunque este factor ha sido considerado en algunas modalidades, solo ha resultado favorecedor en el análisis probabilístico del español de Puerto Rico, La Habana y Santo Domingo (Claes 2014); en cambio, no ha resultado favorecedor en Valencia (Gómez Molina 2013) ni en otro estudio sobre el habla de Puerto Rico (Brown y Rivas 2012).

\subsubsection{Tiempo verbal}

Si bien los estudios lingüísticos han demostrado que la pluralización de haber está muy extendida en muchas comunidades de habla - con una tendencia a la incrementación - lo cierto es que también han señalado que el cambio lingüístico no se está desarrollando en una misma proporción en los distintos tiempos verbales. Por ejemplo, el imperfecto es el tiempo verbal donde el cambio se muestra más avanzado en el habla de los puertorriqueños (Brown y Rivas 2012), venezolanos (Bentivoglio y Sedano 1989, DíazCampos 2003), y salvadoreños (Quintanilla 2009), por citar algunos casos. Esta característica fue la más significativa en el análisis probabilístico del habla de los salvadoreños (.70, según Quintanilla 2009: 173).

En nuestro estudio, este factor fue descartado del análisis probabilístico debido a que el verbo haber siempre se presentó pluralizado en los pocos casos con el pretérito $(n=7 ; 100 \%)$. Esto se debe a que, cuando una celda contiene el valor de $0 \%$ o 100\%, el programa 
lo etiqueta como KnockOut. Por consiguiente, el factor debe eliminarse o recodificarse para que el análisis probabilístico pueda desarrollarse. En nuestro caso, se decidió quitar este factor, debido a que los demás contextos resultaron muy escasos y solo iban a permitir extraer conclusiones superfluas que no se ajustaban a la realidad de los datos.

En nuestros datos, además de la pluralización de haber señalada en la totalidad de los ejemplos del pasado simple, el imperfecto de indicativo fue la variante más común con un $66 \%(n=127)$. La mayor presencia del imperfecto se justifica porque este tiempo suele ser muy frecuente al contar hechos del pasado. No obstante, además del imperfecto $(.53, \mathrm{n}=274)$, en la comunidad valenciana se ha demostrado que la concordancia está fuertemente favorecida en el imperfecto de subjuntivo $(.77, \mathrm{n}=18)$ y en el condicional simple $(.59, \mathrm{n}=21)$ (Blas Arroyo 2016).

\subsection{Factores sociales}

A pesar de que en otras comunidades de habla se ha señalado la relevancia de los factores sociales en la pluralización de haber, en esta investigación solo resultó significativa la edad en el análisis de regresión múltiple. No obstante, se resaltarán algunas tendencias generales que se observan entre las otras variables influyentes.

\subsubsection{La edad}

Como se ha apuntado, la edad fue el factor social más significativo entre el conjunto de factores socioestilísticos estudiados. En el modelo probabilístico diseñado según los datos de nuestra población, el fenómeno se presenta en todas las generaciones: aunque parece ser muy común entre los adolescentes (.51), en realidad, el cambio está especialmente liderado por los jóvenes (.63). El fenómeno se muestra menos favorecido entre los adultos (.40) y los pre-adolescentes (.36).

La edad de llegada es fundamental en los estudios del contacto dialectal. Labov (1972) y Trudgill (1986) están de acuerdo con que, en los procesos de acomodación, un niño puede integrarse total- 
mente en una comunidad de habla hasta los ocho años y, después de esa edad, la integración no es total. Trudgill, incluso, señala que “después de los 14 años no lo harán” (1986: 34). Esta hipótesis justifica el hecho de que la concordancia sea más favorecida entre los adolescentes (15-18 años) y los jóvenes (19-39 años). Por tanto, de acuerdo con la dinámica del cambio lingüístico que se observa al estudiar la edad, es poco probable que al aumentar la edad de los hablantes haya una convergencia hacia el haber impersonal característico de la variedad receptora.

Por otro lado, el hecho de que los menos favorecedores sean los pre-adolescentes quizá esté asociado a la presión normativa escolar que corrige los usos lingüísticos considerados vulgares o estigmatizados desde la variedad madrileña. Esto se puede apreciar en los comentarios de dos informantes de estas edades que se presentan en (16).

(16) Eso me lo han corregido mucho aquí los profesores. Dizque cuando dicen “¿habían deberes?” No, no es habian. (mujer, 8-14 años, 3-4 años de estancia, nivel bajo, 97)

Es que ahora yo estoy enredada [confundida] porque el profe dice que se dice habia y ahora nosotros decimos habian, pero normalmente yo decía habian. (mujer, 8-14 años, 3-4 años de estancia, nivel bajo, 59)

En algunas comunidades de habla como la de Venezuela (DíazCampos 2003), la variante vernacular no presenta diferencias sólidas entre las generaciones observadas, por lo que el autor explica que ello se debe al nivel de extensión del fenómeno. Sin embargo, en consonancia con nuestros datos, en otros estudios posteriores de esta misma comunidad se demostró que la pluralización de haber está más asentada en los hablantes más jóvenes —entre 14-29 años-(D’Aquino Ruíz 2004, 2008). En lo concerniente a Valencia, Blas Arroyo (1996) señala que los casos de pluralización estén más correlacionados con los ancianos (más de 70 años) y después con los jóvenes (15-25 años). 


\subsubsection{El sexo}

Según el sexo, los resultados demuestran que la concordancia existencial está muy extendida entre los dominicanos en Madrid. Esto se debe a que tanto los hombres (.50) como las mujeres (.49) lograron índices de probabilidad muy cercanos, lo que permite determinar la falta de significancia de este factor. Los mismos índices de probabilidad fueron obtenidos en el habla de los salvadoreños en esta variable independiente (Quintanilla 2009). No obstante, en otras comunidades como en Venezuela (Bentivoglio y Sedano 1989) y El Hierro (Canarias) (Pérez Martín 2007), la variante de mayor prestigio, el haber impersonal, se observó entre las mujeres y la variante vernacular entre los hombres.

\subsubsection{El nivel de instrucción}

Respecto al español de América, comúnmente se ha señalado que este fenómeno se asocia a las hablas más vulgares (Alarcos 1999: 275) y populares (Lope Blanch 1995: 22). En este sentido, el análisis del nivel de instrucción ha demostrado que la concordancia existencial está más extendida en los niveles más bajos en el habla espontánea de los salvadoreños (Quintanilla 2009: 172) y en Valencia (Blas Arroyo 1996, 2016).

En la muestra, la categoría <nivel bajo > estuvo representada por 9 dominicanos con un nivel académico equivalente a la educación primaria española; el <nivel medio $>$ lo conformaron 60 con el grado académico equivalente a la ESO y el Bachillerato español, y <nivel alto $>$ tuvo una representación de 31 informantes que han cursado educación superior.

En los resultados del análisis multivariante, se pudo observar que el nivel medio (.44) favorece menos la forma plural de haber, mientras que el nivel bajo (.60) y el nivel alto (.59) presentaron cifras muy similares. La confluencia clase alta-baja resulta compleja de explicar, pero no es tan rara ni sociológica ni sociolingüísticamente: por ejemplo, la intención y tipo de voto suele coincidir en clase alta y baja, las cuales son más conservadoras que la media, y en los patrones sociolingüísticos típicos de Labov, ya que la que se separa 
más siempre es la clase media, aunque sea por hipercorrección. Asimismo, en el caso español, la clase alta suele ser muy populachera, lo cual, desde el punto de vista sociolingüístico, ha favorecido que se arraiguen en Madrid algunos fenómenos meridionales como la pérdida de la -s y la -/d/- intervocálica (Molina 2009: 7). Incluso, se ha señalado que los universitarios lideran la elisión específicamente en los participios en -ado (Molina y Paredes 2014: 78). Montes de Oca (1994) obtuvo una tendencia similar en la variable grupo socio cultural (GSC) y, aunque la concordancia fue mayor en el GSC bajo, el segundo factor mayoritario fue el GSC Alto (36\%) y finalmente el GSC Medio (25\%). La autora justifica estos resultados aludiendo a que los de nivel alto tienen una conciencia lingüística mayor que "les permite hacer una reflexión sobre la lengua que les lleva a la regularización de estos tipos de sintagmas” (1994: 21).

A pesar de las posibles interpretaciones de nuestros datos, cabe recordar que la misma no fue significativa en el análisis de regresión múltiple y, además, alcanzó uno de los niveles más bajos en la Fuerza relativa (relative strength) que se determina a través del rango.

\subsubsection{El tiempo de estancia}

Esta variable, junto al nivel de instrucción, constituyeron las variables de menor rango en la jerarquía explicativa de los factores estudiados. Contrario a lo que podría esperarse, el mayor tiempo de estancia no resulta en un mayor abandono de los usos vernaculares de haber. Por el contrario, la pluralización de haber se presenta ligeramente favorecida por los de 3-4 años de estancia (.51) y los de estancia de 5 años o más (.53). Los de 1-2 años de estancia (.37) fueron los que menos favorecieron la correlación de los factores.

El mantenimiento de la variante vernacular podría estar relacionado a la baja frecuencia de la variable estudiada en el habla cotidiana. Esta hipótesis puede comprobarse considerando el total de palabras que constituyen el corpus general estudiado y determinando el porcentaje de casos presentes de la variable observada. Siguiendo esta propuesta, en nuestro corpus, por ejemplo, de las más de 200,000 palabras que lo conforman, los casos analizados 
de haber solo representaron un $0,15 \%$ de aparición. Por tanto, es probable que esta baja frecuencia desfavorezca el contacto con la variante de la variedad receptora que lleve al informante a reflexionar respecto a su propio uso de la variable. Esta situación se puede comparar con los resultados obtenidos por Peralta Céspedes (2015b) con otra variable gramatical: los tiempos de pretérito perfecto simple y compuesto. La variable observada por el investigador es más llamativa y frecuente en el habla. Por consiguiente, es más fácil para el informante distinguir entre su uso particular y el uso en la comunidad receptora. Peralta observó que los dominicanos en Madrid con tres años o más de residencia utilizaban más el Pretérito Perfecto Compuesto, que es la variante predominante en la norma madrileña, y que los de menor estancia utilizaban más el Pretérito Perfecto Simple, manteniendo el uso propio de su habla vernácula.

La mayor frecuencia de la variable receptora influye doblemente en el hablante: primero, en la exposición de la variante estándar en la comunidad lingüística receptora; por tanto, la exposición constante generará actitudes positivas o negativas hacia el fenómeno en el inmigrante; segundo, en la actuación, ya que él mismo tendrá que decidir en su propia habla cuál variante utilizará. Un ejemplo de ello fue el aumento de la -s implosiva — una variable de alta frecuencia en el habla cotidiana - en los inmigrantes dominicanos en Madrid, en quienes se observó una convergencia con la variante estándar madrileña de 48,8\%, en comparación con los porcentajes de usos que se han datado en el habla de los dominicanos en la República Dominicana (7\%), según apunta Peralta Céspedes (2015b).

En otro orden, es probable que no surjan esas inquietudes en aquellas variables que tienen poca frecuencia en el habla cotidiana. Es probable, además, que el inmigrante nunca perciba el uso estándar en la variedad receptora, salvo que alguien se lo corrija (como sucedió con la informante 97 en el entorno escolar, citado en 16). Incluso, si se enterara, el informante podría elegir no utilizar la variante receptora ya que ella no supondría una distancia lingüística significativa respecto al habla de la comunidad de acogida, precisamente debido a las pocas veces que se utiliza al hablar. 


\section{Discusión}

Nuestro estudio apunta a uno de los desarrollos menos atendidos en las investigaciones de lingüística de la migración: la invariación. Quizá la razón por la que no suele atenderse la invariación se deba a la naturaleza misma de la metodología sociolingüística, la cual se enfoca en el estudio la variación. No obstante, como la lingüística de la migración surge para abordar los aspectos lingüísticos y sociolingüísticos de los procesos migratorios y las situaciones resultantes de los contactos de variedades (Stehl 2011), sería interesante también observar explícitamente la invariación, con el propósito de enriquecer nuestro conocimiento sobre los procesos de adquisición dialectal y el desarrollo de la 'percepción selectiva' a la que alude Caravedo (2009), la cual está muy presente en los contextos migratorios.

El concepto de invariación señalado aquí debe entenderse dentro del contexto migratorio del que forma parte el corpus de la muestra analizada. La invariación refiere al desarrollo a través del cual una comunidad de habla, en un espacio distinto al de la tierra natal, mantiene la variante de uso mayoritaria en su variedad materna. Este concepto no debe confundirse con el de divergencia que se ha propuesto en la teoría de la acomodación del habla (Giles et al. 1973), debido a que los procesos de divergencia requieren de una actitud consciente del hablante a alejarse de las características de habla del D2 (Moreno Fernández 2009: 155). La invariación en el contexto migratorio abarca los procesos conscientes e inconscientes de mantenimiento de la variante de origen. Por ahora, dejo para otra ocasión la discusión de este concepto y sus posibles aplicaciones en el estudio de la lingüística de la migración.

Si asumimos que la percepción selectiva se reactiva en los contextos migratorios, también debemos asumir que se reactivan los procesos cognitivos de aprendizaje lingüístico, debido a la interrelación que existe entre percepción y cognición (Caravedo 2014: 56). Así, aunque el inmigrante hable la misma lengua que se habla en la población receptora, seguramente observará diferencias con 
su dialecto materno, muchas de las cuales tendrá que aprender, según su motivación, necesidades y circunstancias, y otras, no las aprenderá.

Ahora bien, ¿qué hace posible la invariación? ¿por qué algunas variantes del D1 tienden a mantenerse en el contexto migratorio? Si se observa la invariación en los contextos migratorios, los estudios de lingüística migratoria contribuirán a responder esta compleja cuestión.

Krefeld (2019) distingue entre variantes marcadas ${ }^{6}$ y neutras. Las variantes marcadas son usos sobresalientes que están asociados a una de las dimensiones de la lengua (diatópica, diafásica, diastrática, diamesia). Las variantes neutras, por el contrario, no se asocian a ninguna de las dimensiones lingüísticas. Adoptando la perspectiva de este autor, esta distinción puede ayudar a explicar desde un enfoque metacognitivo la invariación a la que nos hemos referido. De esta manera, las variantes marcadas en el D1 tenderán a la variación (Bortoni-Ricardo 1985: 175), mientras que las neutras tenderán a la invariación.

No debería sorprendernos que algunas características del D1 no resulten influidas por el D2 en los contextos migratorios. Como indica Caravedo: "no todos los rasgos propios de las lenguas suscitan valoraciones marcadas [... debido a que] no es posible percibir absolutamente todas las características de la propia lengua [...]" (2010: 12).

La pluralización de haber se comporta como una variante neutra en el español de la República Dominicana. Alba (2004: 134) señala que es general en todos los niveles sociales de este país y que está muy extendida y arraigada aún en los círculos intelectuales. Aunque Claes (2015: 20) indica que está más extendida en la clase media $(53.8 \%, \mathrm{n}=248)$, son también frecuentes los usos en la clase alta $(43.3 \%, \mathrm{n}=311)$ y la clase baja $(45.5 \%, \mathrm{n}=301)$.

\footnotetext{
El concepto de variante marcada se relaciona con el de marcadores de William Labov. Ambos términos describen una misma realidad, pero se explican desde distintas perspectivas, ya que, para Labov, los marcadores son variables sociolingüísticas, mientras que Krefeld los enfoca desde la variación perceptiva.
} 
Dado que en nuestro corpus de los dominicanos en Madrid se mantienen los porcentajes generales de uso de los dominicanos en la República Dominicana, se comprueba la invariación de la variable en el contacto con la variedad madrileña, la cual puede deberse al carácter neutro de la variante.

Desde una dimensión cognitiva, el carácter neutro de la variante pluralizada se favorece por la noción semántica de número en el núcleo de la FN. Esto deriva de la siguiente explicación que a menudo presentan algunos informantes para justificar la concordancia verbal: "[se dice] habían, porque son varias" (Informante 64, mujer). Por tanto, es muy probable que se utilice la variante pluralizada cuando el CD, que es reinterpretado como sujeto por los hablantes en las oraciones impersonales con haber (Hernández Díaz 2006), refiera a un elemento susceptible a interpretarse con número plural. La noción semántica de número señalada lleva al hablante a usar la pluralización de haber ante entidades colectivas (e.x habian gente), ante numerales sin núcleos explícitos (e.x habian cuatro [amigos]) y ante la pérdida de la -s en los determinantes y los sustantivos de la FN (e.x babian uno(s) cuanto(s) jóvene(s)), como se presentó en la Tabla 2.

Por otro lado, cabe señalar que en la observación y el estudio de la variación y la invariación en los procesos migratorios son importantes el nivel de percepción y el nivel de frecuencia de la variable. Aunque puede existir una correlación entre los dos conceptos, no siempre es así. Consideremos como ejemplos la palabra juale! y la di un regalo (a María). Un inmigrante no lingüista seguramente afirmaría que vale cuenta con un alto nivel de percepción debido a su frecuencia; sin embargo, la di un regalo tendría un alto nivel de percepción, pero no una alta frecuencia como vale. Otra diferencia es que el nivel de percepción no solo depende de la frecuencia, sino también de otros factores como el nivel de instrucción, el dominio de otras lenguas o dialectos y el contacto con otros dialectos, ya que, se ha demostrado en los estudios en categorización dialectal que las personas que han tenido experiencia personal con otras variedades desarrollan una mayor percepción lingüística que les 
permite identificar con mayor facilidad las diferencias dialectales (Clopper y Pisoni 2005: 325).

La frecuencia de la variable ha sido analizada como una característica del sistema lingüístico que facilita observar la variación y el cambio lingüístico (Bybee 2002, Díaz-Campos y Ruíz-Sanchez 2008). Se considera la importancia de este factor, además, en la planificación de la enseñanza de una lengua (Leech 2001). Asimismo, como se señaló más arriba, la frecuencia de la variable constituye una de las características que puede desencadenar las actitudes hacia un fenómeno lingüístico (Preston 2013)

Estas diferencias, por lo tanto, nos permiten afirmar que la percepción y la frecuencia pueden considerarse como factores distintos en los estudios lingüísticos migratorios, los cuales pueden interrelacionarse, pero no en todos los contextos. Por ello, es interesante señalar que los procesos de convergencia y divergencia que se producen en el contacto dialectal dependen, entre otros factores, de a) el nivel de frecuencia con el que se presente la variable en el discurso $\mathrm{y}$ de b) el nivel de percepción que el hablante tenga de la variable. En este sentido, es más probable que se observen los procesos de convergencia o divergencia cuando la variable presente un mayor nivel de frecuencia en el discurso y, por el contrario, es menos probable que se observen estos procesos cuando la variable muestre una frecuencia menor. Asimismo, el nivel de percepción puede ser proporcional al nivel de frecuencia, aunque el factor percepción esté fuertemente vinculado también a otros factores como la red social del hablante y a las intenciones de integración con la población receptora. Denominamos hipótesis de la percepción de la variable a la relación señalada entre el nivel de frecuencia y el nivel de percepción en los procesos del contacto dialectal. Esta se ilustra en la Figura 2.

Figura 2. Hipótesis de la percepción de la variable + Frecuencia + percepción $=+$ convergencia/divergencia - frecuencia - percepción $=$ - convergencia/divergencia 
La hipótesis de la percepción de la variable permite describir la falta de correlación entre la pluralización de haber con el tiempo de estancia y el nivel de instrucción en este estudio. Si en el habla de Madrid no existe prácticamente la pluralización de haber, ¿ por qué los migrantes dominicanos mantienen tan fuertemente este uso a pesar del tiempo de estancia y del nivel de instrucción de los hablantes? Esto puede deberse a dos factores, a mi entender:

A. Que la menor frecuencia del haber impersonal como variante sintáctica resulta en una menor percepción de la variante y, en consecuencia, hace menos probable la convergencia o el proceso de acomodación.

B. Que la concepción de haber como verbo intransitivo está tan arraigada en la percepción de los dominicanos que impide que la forma impersonal alcance mayores niveles de frecuencia.

Respecto a los factores sociales, pareciera que en los resultados puede haber una interacción entre la edad y los años de educación. Esta hipótesis se sustenta en el hecho de que los jóvenes tienen menos años de educación que los adultos. Sin embargo, este argumento no se ajusta a la estructura social de la muestra estudiada, ya que, de 31 informantes con un nivel de instrucción alto, 21 eran jóvenes y solo 10 eran adultos. Por lo tanto, en la muestra analizada, los jóvenes tienen una educación mayor que los adultos. Esto se debe a las características socioculturales de la población estudiada, la cual está fuertemente influida por los tipos de inmigrantes que se han movilizado a España en las últimas cuatro décadas. Como ha resaltado Pimentel (2001), los dominicanos que emigraron a partir de 1985 tenían un nivel de instrucción bajo; en cambio, los que han emigrado desde principio del siglo XXI son estudiantes universitarios que aprovechan las oportunidades de estudios que se les presentan a través de los acuerdos gubernamentales que se han firmado entre ambos países.

Otra aparente interacción sería la edad y el tiempo de residencia en Madrid. Así, podría pensarse que las personas de mayor edad tienen un mayor tiempo de residencia en la comunidad de acogida. 
Creemos que dicha interacción hubiera sido posible si el rango de tiempo en Madrid hubiera sido mayor, como 1-5 años, 6-10 y 11-15 años. Sin embargo, como se presentó en la metodología (apartado 2), el rango de tiempo preestablecido fue menor (1-2 años, 3-4 años y mayor de 5 años). Por consiguiente, tanto un informante de 8 años como el mayor de 40 podrían cumplir con el mayor tiempo de residencia de 5 años. Lo que hemos explicado brevemente se observa en la población estudiada en las personas con más de 5 años de residencia, la cual estuvo representada mayoritariamente por los jóvenes (23 informantes) y después por los adultos (17 informantes); asimismo, entre los informantes con 3-4 años de residencia, hubo 6 pre-adolescentes y solo 1 adulto. Por tanto, las personas de mayor edad no mostraron mayor tiempo de residencia en la población estudiada.

La frecuencia de la variable tiene una gran importancia en la planificación metodológica de los futuros estudios en el contacto dialectal, ya que facilitaría la observación de la convergencia o divergencia con la variedad receptora.

\section{Conclusión}

La investigación presentada ha mostrado que la pluralización de haber es la variante mayoritaria entre los dominicanos con estancia en Madrid, a pesar de que, en la modalidad madrileña, considerada de mayor prestigio, predomine la variante de haber impersonal.

Una aportación singular de este estudio es que, aunque el contacto con la variedad madrileña ha resultado influyente en la reducción de algunas variantes vernaculares - como la neutralización de la evidencialidad de las formas verbales de pasado entre los ecuatorianos en Madrid (Palacios 2007: 121) o el mayor uso del pretérito perfecto compuesto en lugar del pretérito perfecto simple entre los dominicanos en Madrid (Peralta 2015: 722), por citar solo algunos ejemplos- en nuestro caso no se observa dicha influencia, debido a la naturaleza de la variable. Por tanto, se ha comprobado que no existe un proceso de acomodación de los dominicanos hacia el habla 
madrileña en este aspecto. La hipótesis de la percepción de la variable ha servido para intentar explicar este fenómeno. Como se expuso brevemente, esto puede estar asociado a la menor percepción de la variante de prestigio en Madrid; también puede deberse al mayor arraigo de la pluralización de haber entre los migrantes dominicanos.

En el análisis probabilístico, la variante resultó significativamente favorecida por las marcas de pluralidad de la FN, por la posición pospuesta de la FN, por los jóvenes y adolescentes. La pluralización de haber se observó más en el imperfecto y en el pretérito. Sin embargo, no resultaron determinantes los siguientes factores: rasgo semántico de la FN, estructura verbal, sexo, ocupación, nivel de instrucción ni estilo.

Queda pendiente observar si la hipótesis de la percepción de la variable, propuesta en este estudio, se comprueba entre otros grupos de inmigrantes y con otras variables.

\section{Referencias bibliográficas}

Al-Banyan, Ahmed and Dennis Preston

1998 "What is Standard American English?". Studia Anglica Posnaniensia. 33. 29-46.

Alarcos Llorach, Emilio

1999 Gramática de la Lengua Española. Madrid: Espasa Calpe.

Alba, Orlando

2004 Cómo hablamos español los dominicanos. Santo Domingo: Amigos del hogar.

Almeida, Manuel y Carmen Díaz Alayón

1989 El español de Canarias. Santa Cruz de Tenerife: Ed. de los autores.

Bentivoglio, Paola y Mercedes Sedano

1989 "Haber. ¿Un verbo impersonal? Un estudio sobre el español de Caracas". En Estudios sobre el Español de América y Lingüística Afroamericana: Ponencias Presentadas en el 45 Congreso Internacional de Americanistas. Bogotá: Instituto Caro y Cuervo, 51-81. 
Bentivoglio, Paola y Mercedes Sedano

1992 “El español hablado en Venezuela”. En Historia y Presente del Español de América. Coord., César Hernández Alonso. Valladolid: Junta de Castilla y León, 775-801.

Bentivoglio, Paola y Mercedes Sedano

1996 “Tres casos de variación morfosintáctica en el español actual”. Lexis. XX. 1-2, 165-184.

Blas Arroyo, José Luis

1996 "A propósito de un caso de convergencia gramatical por causación múltiple en el área de influencia lingüística catalana. Estudio sociolingüístico". Cuadernos de Investigación Filológica. 21. 175-200. <https://doi.org/10.18172/cif.2356>

Blas Arroyo, José Luis

2016 "Entre la estabilidad y la hipercorrección en un antiguo 'cambio desde abajo': Haber existencial en las comunidades castellonenses”. Lingüística Española Actual (LEA). 38. 1, 69-108.

BORTONI-RicARdo, Stella Maris

1985 The Urbanization of Rural Dialect Speakers: A Sociolinguistic Study in Brazil. Cambridge: Cambridge University Press.

BYBEE, Joan

2002 "Word frequency and context of use in the lexical diffusion of phonetically conditioned sound change". Language Variation and Change. 14. 261-290. <https://doi.org/10.1017/ S0954394502143018>

Caravedo, Rocío

2009 "La percepción selectiva en situación de migración desde un enfoque cognoscitivo". Lengua y migración / Language $\mathcal{E}$ Migration. 1-2, 21-38.

Caravedo, Rocío

2010 "La dimensión subjetiva en el contacto lingüístico". Lengua y migración / Language E Migration. 2-2, 9-25.

Caravedo, Rocío

2014 Percepción y variación lingüística. Enfoque sociocognitivo. Frankfurt-Madrid: Vervuert-Iberoamericana. 
Chambers, Jack

1992 “Dialect acquisition”. Language. 68. 673-705. <https://doi. org/10.1353/lan.1992.0060>

Claes, Jeroen

2014 The pluralization of presentational haber in Caribbean Spanish. Tesis doctoral. Antwerpen: Universiteit Antwerpen. Consultado: 13 de mayo de 2017. <https://core.ac.uk/ download/pdf/80810446.pdf>

Claes, Jeroen

2015 "Competing constructions: The pluralization of presentational haber in Dominican Spanish". Cognitive Linguistics. 26. 1, 1-30. https://doi.org/10.1515/cog-2014-0006.

Clopper, Cinthia y David Pisoni

2005 "Perception on dialect variation". En The Handbook of speech perception. Eds., David Pisoni y Robert E. Remez. Australia: Blackwell, Publishing, Ltd.

Colombo, Fulvia, y María Ángeles Soler

2003 “EErrores morfosintácticos en el español escrito? En Cambio lingüistico y normatividad. Coord., Fulvia Colombo y María Ángeles Soler. México: Instituto de Investigaciones Filológicas, Universidad Nacional Autónoma de México (Publicaciones del Centro de Lingüística Hispánica, 49).

Cramer, Jennifer

2016 "Perceptual dialectology". Oxford Handbooks Online. Linguistics. New York: Oxford University Press.

D’Aquino Ruiz, Giovanna

2004 "Haber impersonal en el habla de Caracas. Análisis sociolingüístico”. Boletín de Lingüística. 21. 3-26.

D’Aquino Ruiz, Giovanna

2008 "El cambio lingüístico de haber impersonal”. Núcleo. 25. 103123.

Demello, George

1991 "Pluralización del verbo haber impersonal en español hablado culto de once ciudades". Thesaurus. 46. 445-471. 
Díaz-Campos, Manuel

1999-2000 "La pluralización del verbo haber en dos áreas dialectales de Hispanoamérica”. Anuario de Lingüistica Hispánica. 15,16, 235-245.

2003 "The pluralization of haber in Venezuelan Spanish: A sociolinguistic change in real time". IU Working Papers in Linguistics. 3. 5, 1-13.

Díaz-Campos, Manuel y Carmen Ruiz Sanchez

2008 "The Value of Frequency as a Linguistic Factor: The Case of Two Dialectal Regions in the Spanish Speaking World”. En Selected Proceedings of the 4th Workshop on Spanish Sociolinguistics. Eds., Maurice Westmoreland y Juan Antonio Thomas. Somerville, MA: Cascadilla Proceedings Project, 43-53.

Domínguez, Carmen Luisa, Blanca Guzmán, Luis Moros, Maryeris PABÓn y Roger Vilaín

1998 "Personalización de haber en el español de Mérida". Lengua y Habla. 3. 1, 23-36.

Foreman, Annik

2000

"A longitudinal study of Americans in Australia". En Proceedings of ALS2K, the 2000 Conference of the Australian Linguistics Society. Eds., Keith Allen y John Henderson. Consultado: 08 de abril de 2020. <http://www.als.asn.au/ proceedings/als2000/foreman.pdf>

Freites-BARRos, Francisco

2008 "Más sobre la pluralización de haber impersonal en Venezuela. El estado Táchira”. Lingua Americana. 22. 36-57.

Giles, Howard, Donald Taylor y Richard Bourhis

1973 "Toward a theory of interpersonal accommodation through language: some Canadian data”. Language in Society. 2. 2, 177192. <https://doi.org/10.1017/S0047404500000701>

Gómez Molina, José Ramón

2013 "Usos del verbo haber impersonal". El español de Valencia, Estudio sociolingüistico. Bern: Peter Lang, 109-143.

GoOdman, Leo

1961 "Snowball sampling". Annals of Mathematical Statistics. 32. 1, $148-170$. 
GugENBERgER, Eva

2006 "Migrationslinguistik: Akkulturation, Sprachverhalten und sprachliche Hybridität am Beispiel galicischer Immigranten und Immigrantinnen in Argentinien”. Tesis de habilitación. Universidad de Bremen.

Henríquez Ureña, Pedro

1939 “Ello”. Revista de Filología Hispánica. 1. 3, 209-229. <https:// doi.org/10.24201/nrfh.v18i1/2.1556>

Hernández Alonso, César

1975 Sintaxis española. Valladolid: edición del autor, $3^{a}$ edición.

Hernández Díaz, Axel

2006 "Gramaticalización y reanálisis. La concordancia del verbo 'haber' existencial en la diacronía del español”. En Actas del VI Congreso Internacional de Historia de la Lengua Española. Coords., José Luis Girón Alcochel y José Jesús Busto Tovar. Madrid: Arco Libros. 799-811.

Hernández DíAz, Axel

2014. "Funciones discursivas de las oraciones existenciales en español”. Anuari de Filología. Estudis de Lingüística. 119-138.

HinZelin, Marc-Olivier y Georg A. Kaiser

2007 "El pronombre ello en el léxico del español dominicano". En Language contact and language change in the Caribbean and beyond. Eds., W. Mihatsch y M. Sokol. Frankfurt am Main: Lang, 171-188. Consultado: 12 de mayo de 2020. <https://dnb.info/1093432330/34>

Holmes, Janet y Paul Kerswill

2008 Contact is not enough: a response to Trudgill. Language and Society. 37. 2, 273-277.

INOUE, Fumio

1996 "Subjective dialect division in Great Britain". American Speech. 71. 2, 142-161. <https://doi.org/10.2307/455482>

Jiménez Sabater, Max Arturo

1975 Más datos sobre el español de la República Dominicana. Santo Domingo: Ediciones Intec. 
KanY, Charles

1976 Sintaxis Hispanoamericana. Madrid: Gredos.

Kerswill, Paul

1992

"Some principles of dialect contact: evidence from the New Town of Milton Keynes”. En Working Papers 1992. Eds.,

I. Philippaki-Warburton y R. Ingham. Dept. of Linguistic Science: University of Reading, 68-90.

Kerswill, Paul

1994 Dialects Converging: Rural Speech in Urban Norway. Oxford: Clarendon Press.

Kluge, Bettina

2005 Identitätskonstitution im Gespräch: Südchilenische Migrantinnen in Santiago de Chile. Madrid/Frankfurt: Iberoamericana/Vervuert.

KREFELD, Thomas

2004 Einfübrung in die Migrationslinguistik: Von der Germania italiana in die Romania multipla. Tübingen: Narr.

KREFELD, Thomas

2019 "Sprachliche Variation und Perzeption". Version 1. Lehre in den Digital Humanities. Consultado: 06 de septiembre de 2019. <https://www.dh-lehre.gwi.uni-muenchen. $\mathrm{de} / \mathrm{p}=149541 \& \mathrm{v}=1>$

LABOV, William

1972 Sociolinguistic Patterns. Filadelfia: University of Pennsylvania Press.

LANGACKER, Ronald

1977 "Syntactic reanalysis". En Mechanisms of Syntactic Change. Ed., Charles N. Li. Austin: Texas University Press, 57-139.

Lastra, Yolanda y Pedro Martín Butragueño

2016 "La concordancia de haber existencial en la ciudad de México". Boletín de Filología. 121-145.

LEECH, Geoffrey

2001 "The role of frequency in ELT: New corpus evidence brings a re-appraisal". En ELT in China 2001: Papers presented at the 3rd International Symposium on ELT in China. Beijing: Foreign Language Teaching and Research Press, 1-23. 
Lope Blanch, Juan Manuel

1995 "El problema de la lengua española de América". Nueva Revista de Filología Hispánica. XLIII. 1, 17-36.

Martínez, José Antonio

"La concordancia”. Tomo 2. En Gramática descriptiva de la lengua española. Tomo 2. Coords., Violeta Demonte e Ignacio Bosque. Madrid: Espasa Calpe, 2695-2786.

Milroy, Lesley

1987 Language and Social Networks. Oxford: Blackwell.

Molina Martos, Isabel

2009 Sociolingüística del español de Madrid. Disponible en <www. liceus.com>

Molina Martos, Isabel y Florentino Paredes García

2014 "Sociolingüística de la elisión de la dental /d/ en Madrid (Distrito Salamanca)”. Cuadernos de Lingüística. 2, 55-114. $<$ https://doi.org/10.24201/clecm.v2i0.15>

Montgomery, Chris

2007 "Northern English Dialects: A Perceptual Approach". Tesis doctoral. University of Sheffield, UK.

Montes de Oca, Pilar

1994 La Concordancia con Haber Impersonal. Tesis. Universidad Nacional Autónoma de México.

Moreno Fernández, Francisco

1999-2000 "El estudio de la convergencia y la divergencia dialectal". Revista Portuguesa de Filología. 23. 1-27.

Moreno FernándeZ, Francisco

2009 Principios de sociolingüística y sociología del lenguaje. Barcelona: Ariel.

Morgenthaler García, Laura

2006 "Dialecto, estándar y construcción de la identidad en zonas periféricas. Estudio sociolingüístico sobre el estatus del español de Canarias". Tesis doctoral. Universidad de Bremen. (publicado como: Identidad y pluricentrismo lingüístico. Hablantes canarios frente a la estandarización. Madrid/Frankfurt: Iberoamericana/Vervuert 2007). 


\section{NieDZIELSKI, Nancy}

1999 "The effect of social information on the perception of sociolinguistic variables". Journal of Language and Social Psychology. 18. 1, 62-85. <https://doi.org/10.1177/026192 7X99018001005>

Palacios Alcaine, Azucena

2007 "Cambios lingüísticos de ida y vuelta: los tiempos de pasado en la variedad emergente de los migrantes ecuatorianos en España”. En Revista Internacional de Lingüistica Iberoamericana (RILI). 5. 2, 109-125.

Paredes García, Florentino

2016 “La pluralización del verbo 'haber' existencial en Madrid: ¿etapas iniciales de un cambio lingüístico?”. Boletín de Filología. 51. 2, 209-234. <https://doi.org/10.4067/S071893032016000200008>

Peralta Céspedes, Manuel

2015a "El cambio fonológico brusco: sobre la /s/ implosiva de los dominicanos en Madrid". En La Española - Isla de Encuentros. Hispaniola - Island of Encounters. Eds., Jéssica Barzen, Hanna Lene Geiger y Silke Jansen. Narr, 197-215.

Peralta Céspedes, Manuel

2015b "Los tiempos de pretérito en el habla de los dominicanos en Madrid: estudio sociolingüístico". En Jóvenes aportaciones a la investigación lingüística. Ed., Blanca Garrido Martín. Universidad de Sevilla, 709-724.

Peralta Céspedes, Manuel

2016 Convergencia y divergencia en el español de bablantes dominicanos en Madrid. Tesis doctoral. Universidad Complutense. <https://eprints.ucm.es/43011/1/T38856.pdf>

Pérez Martín, Ana María

2007 "Pluralización de había en el habla de El Hierro: datos cuantitativos". Revista de Filología de la Universidad de La Laguna. 25. 505-513.

Pimentel, Alcides

2001 "Dominicanos en España. Los dominicanos en Barcelona”. Escripta Nova: Revista Electrónica de Geografía y Ciencias Sociales. 94, 65. 
Plichta, Bartlomiej y Dennis R. Preston

2005 "The /ay/s have It: The perception of /ay/ as a north-south stereotype in United States English". Acta Linguistica Hafniensia. 37. 107-30. <https://doi.org/10.1080/03740463.20 05.10416086>

Poplack, Shana y Sali A. Tagliamonte

2001 African American English in the diaspora: tense and aspect. Malden: Blackwell Publishers.

Preston, Dennis

1989 Perceptual Dialectology. Dordrecht: Foris.

Preston, Dennis (ed.)

1999 “Introduction”. En Handbook of Perceptual Dialectology. Ed., Dennis R. Preston (Amsterdam: John Benjamins), xxiiixxxix.

Preston, Dennis (ed.)

2013 "Language with an attitude". En The Handbook of Language Variation and Change. Eds., Chambers, Jack y Nathalie Schilling, Nathalie. John Wiley \& Sons.

Quilis, Antonio

1983 La concordancia gramatical en la lengua española bablada en Madrid. Madrid: C.S.I.C.

Quintanilla-Aguilar, José Roberto

$2009 L a($ des)pluralización del verbo haber existencial en el español salvadoreño: ¿ un cambio de progreso? Tesis doctoral. University of Florida.

Real Academia Española (RAE)

2005 Diccionario Panhispánico de Dudas (DPD). Madrid: Santillana.

RIVAS, Javier y Esther BROwN

2012 "Concordancia variable con haber en español puertorriqueño”. Boletín de Lingüistica. 24. 102-118.

Robinson, John, Helen Lawrence y Sali Tagliamonte

2001 Goldvarb 2001. Department of Language and Linguistic Science, University of York. Consultado: 15 de mayo de 2017. $<$ http://individual.utoronto.ca/tagliamonte/goldvarb.html> 
SÁez Rivera, Daniel

2014 "El Madrid plurilingüe y pluridialectal: nueva realidad, nuevos enfoques”. En Prácticas y políticas lingüisticas. Nuevas variedades, normal, actitudes y perspectivas. Ed., Klaus Zimmerman. Madrid/Frankfurt am Main: Iberoamericana/Vervuert, 403440 .

Sáez Rivera, Daniel

2015 "Viajes lingüísticos de ida y vuelta: el español de los dominicanos en Madrid y su plasmación en el Paisaje Lingüístico". En La Española - Isla de encuentros, Hispaniola - Island of Encounters. Eds., Jessica Stefanie Barzen, Hanna Lene Geiger y Silke Jansen. Tübingen, Narr Verlag, 171-195.

SIEGEL, Jeff

2010 Second Dialect Acquisition. Cambridge: Cambridge University Press.

Soler Arechalde, María Ángeles

2012 "Pluralización de haber impersonal en el habla culta de varias ciudades hispanoamericanas". Ponencia presentada en el III Coloquio de Cambio y Variación: Geolingüistica. México: INAH - ENAH, octubre.

STEHL, Thomas

2011 "Mobilität, Sprachkontakte und Integration: Aspekte der Migrationslinguistik". En Mobilisierte Kulturen. Themen, Theorien, Tendenzen. Eds., Norbert Franz y Rüdiger Kunow. Potsdam: Universitätsverlang, 33-55.

TAgliamonte, Sali

2002 "Comparative sociolinguistics". En Handbook of language variation and change. Eds., Jack Chambers, Peter Trudgill and Natalie Schilling-Estes. Malden and Oxford: Blackwell Publishers, 729-763.

TAgliamonte, Sali

2006 Analysing Sociolinguistics Variation. New York: Cambridge University.

Trudgill, Peter

1986 Dialects in contact. Oxford: Blackwell. 
VAquero, María

1996 “Las Antillas”. En Manual de dialectología hispánica: el español de América. Dir., Manuel Alvar. Barcelona: Ariel, 51-67.

Zimmermann, Klaus y Laura Morgenthaler García

2007 “¿Lingüística y migración o lingüística de la migración?: De la construcción de un objeto científico hacia una nueva disciplina”. RILI. 10, 7-19.

Recepción: 06/12/2019

Aceptación: 20/08/2020 